\title{
On Nobel Laureate Arvid Carlsson
}

Kjell Fuxe ${ }^{1}$

Published online: 19 March 2019

(C) Springer-Verlag GmbH Austria, part of Springer Nature 2019

Dr. Arvid Carlsson received the Nobel Prize in 2000 along with Drs. Paul Greengard and Eric Kandel for their discoveries concerning "signal transduction in the nervous system". Arvid Carlsson discovered the neurotransmitter dopamine in the brain. Other discoveries were to provide the first indications that dopamine mediated the antiparkinsonian actions of levodopa and that blockade of DA receptors mediated the antipsychotic actions of neuroleptics in the treatment of schizophrenia. These discoveries were made in the 1950s and early 1960s.

As underscored by Arvid Carlsson, the 5 months of training he received in 1955 in the laboratory of Dr. Bernhard B. Brodie, head of the laboratory of Chemical Pharmacology at the National Heart Institute, played a significant role in his discoveries. Dr. Brodie and his team taught Arvid Carlsson new analytical methods involving the use of the AmincoBowman spectrophotofluorimeter.

In spite of his discoveries his work was regarded with skepticism at the Ciba Foundation Symposium on Adrenergic Mechanisms held in London in 1960. The reason: dopamine was not regarded to be a neurotransmitter according to the criteria the leaders in the field of transmission had introduced, especially Nobel Laureate Henry Dale, who was present at the meeting. However, a paradigm shift developed in the early 1960s (1962-1965) with the evidence obtained for the existence of central monoamine neurons based on the Falck-Hillarp formaldehyde fluorescence technique for the cellular localization of monoamines. As a result, as early as the late 1960s, the discoveries made by Arvid Carlsson were accepted as representing pioneering work.

From this period until his death in 2018, Arvid Carlsson has been one of the true international leaders in the field of neuropsychopharmacology. He worked with CINP, ACNP and ECNP as well as with the drug industry in an

Kjell Fuxe

Kjell.Fuxe@ki.se

1 Department of Neuroscience, Karolinska Institutet, Biomedicum, Stockholm, Sweden outstanding way to develop novel drugs for treatment of mental disease, especially schizophrenia and depression, and of Parkinson's disease.

I met Arvid Carlsson for the first time in the early 1960s while working on my thesis, entitled "Evidence for the existence of monoamine neurons in the central nervous system", in the Department of Histology, Karolinska Institutet. For this I thank my teacher Dr. Nils-Åke Hillarp, who was the chairman of the department and had a highly productive collaboration with Arvid Carlsson. It was a pleasure and honor to meet Arvid and, in the subsequent cooperative efforts with him and his group in the 1960s, Arvid introduced me into the exciting world of neuropsychopharmacology. I am genuinely grateful for his commitment and crucial support from 1965 to 1968, after Hillarp's death in 1965, 1 month prior to my thesis defense at the Karolinska Institutet.

It feels strange for me not to be able to see him anymore. We met at the conferences almost every year, somewhere in the world. We interacted briefly in a friendly and fruitful way, and we both loved neuropsychopharmacology. I always enjoyed his crystal-clear lectures that helped me understand monoamine pharmacology. Should a scientist raise critical questions, Arvid was always superb in the defense of his work: he had a great fighting spirit. He also possessed a unique analytical capability that all of us admired.

My generation of medical scientists in Sweden was proud that he was a Swede, and we will always remember him as one of the very best in the world in his field.

He leaves an empty space that no one can fill and has our highest respect.

Publisher's Note Springer Nature remains neutral with regard to jurisdictional claims in published maps and institutional affiliations. 